\title{
Accuracy of Ultrasound to Determine Gestational Age in Third Trimester
}

\author{
Hebah A. Falatah1, Ibrahim A. Awad', Hanan Y. Abbas', Maway A. Khafaji², \\ Khalid G. H. Alsafi ${ }^{2}$, Saddig D. Jastaniah ${ }^{1 *}$ \\ ${ }^{1}$ Department of Diagnostic Radiology, Faculty of Applied Medical Sciences, King Abdulaziz University, \\ Jeddah, KSA \\ ${ }^{2}$ Department of Radiology, School of Medicine, King Abdulaziz University, Jeddah, KSA \\ Email: sjastaniah@kau.edu.sa
}

Received 27 June 2014; revised 28 July 2014; accepted 28 August 2014

Copyright (C) 2014 by authors and Scientific Research Publishing Inc.

This work is licensed under the Creative Commons Attribution International License (CC BY).

http://creativecommons.org/licenses/by/4.0/

c) (i) Open Access

\begin{abstract}
Rapid and accurate determination of gestational age (GA) may be vital to the appropriate care of the critically ill pregnant patient and improve obstetric care through allowing the optimal timing of necessary interventions and the avoidance of unnecessary ones. Ultrasound scans are considered to be the most cost-effective, accurate and safe methods for measurement of various fetal parts in pregnant women. The aim of this research is to explore the accuracy of ultrasound in determining gestational age of fetus in third trimesters. Data collected for all pregnant women referred to the Maternity \& Children's Hospital in Jeddah. Only women with single live fetus were included in this study. Women who participated in the study were selected on following criteria: Regular menstrual cycles, known date of last menstrual period and previous live normal neonates in multipara. All scans were performed by a single ultrasonologist on one ultrasound machine. From collected data, it was found that out of $53(100 \%)$ patients, $44(84.62 \%)$ pregnant woman have different gestational age from US and last menstrual period (LMP). From this study we can conclude that the main method to follow fetus growth in third trimester not biparietal diameter (BPD) measurement only. The BPD in third trimester is not reliable and be useless when the patient pass 30 weeks and the BPD has to be side with other measurements when we take it in later trimesters to emphasize the normal growth of fetus and avoid wrong measurement of ultrasound.
\end{abstract}

\section{Keywords}

Ultrasonography, GA, BPD, Third Trimester

\footnotetext{
*Corresponding author.
}

How to cite this paper: Falatah, H.A., Awad, I.A., Abbas, H.Y., Khafaji, M.A., Alsafi, K.G.H. and Jastaniah, S.D. (2014) Accuracy of Ultrasound to Determine Gestational Age in Third Trimester. Open Journal of Medical Imaging, 4, 126-132. 


\section{Introduction}

The accurate dating of pregnancy is critically important for pregnancy management from the first trimester delivery, and is particularly necessary for determining viability in premature labour and in post-dates deliveries $[1]$.

Ultrasonic studies have proven useful in determination of gestational age (GA) in first and second trimester, but their accuracy in third trimester is not reliable because of biologic variations like racial differences in fetal biometric measurements and inter-population variations [2].

Obstetrical (OB) ultrasound technicians routinely measure biparietal diameter (BPD), head circumference, abdominal circumference, and femur length (FL) to estimate gestational age in an outpatient setting [3].

When ultrasound is performed with quality and precision, there is evidence to suggest that dating a pregnancy using ultrasound measurements is clinically superior to using menstrual dating with or without ultrasound, and this has been advocated and adopted in other jurisdictions [4] [5]. Ultrasound estimation of gestational age in the first trimester is therefore more accurate than later in pregnancy [6].

When performed with quality and precision, ultrasound alone is more accurate than a "certain” menstrual date for determining gestational age in the first and second trimesters ( $\leq 23$ weeks) in spontaneous conceptions, and it is the best method for estimating the delivery date [7].

The aim of this research was exploring the accuracy of ultrasonic measurement of biparietal diameter (BPD) and femur length (FL) in assessing gestational age in the third trimester of pregnancy.

\section{Material and Methods}

The study was conducted in 53 pregnant women who came for ultrasonography in the Maternity \& Children’s Hospital in Jeddah. Data collected for all pregnant women referred to the Maternity \& Children’s Hospital in Jeddah. Only women with 20 - 36 weeks CUA (composite ultrasonographic age) till term were included in this study. All patients were examined for any other complication. Gravid females with single live fetus with no complication i.e., congenital anomaly, or growth restriction were included. Women who participated in the study were selected on following criteria: Regular menstrual cycles, known date of last menstrual period .Previous live normal neonates in multipara.

All scans were performed by a single ultrasonologist on one ultrasound machine; a $3.5 \mathrm{MHz}$ sector transducer was used. From the ultrasound reports biparietal diameter measurement was taken and tabulated then analyzed according to the last menstrual period and BPD in ultrasound.

\section{Results}

The study was conducted in 53 women who came for ultrasonography in the third trimester. The maternal age was between 20 - 36 years with a mean maternal age of $25.79 \pm 4$. In $37.5 \%$ of the total cases, it was observed that FL increased gradually from a minimum of $50 \mathrm{~mm}$ at the 27.25 weeks GA to $76 \mathrm{~mm}$ in the 37.43 weeks (Table 1). In 36 - 38 weeks the increase in FL. Data were prepared for BPD in different weeks of gestation in form of Tables and Graphs.

The number of pregnant women have different in gestational age when examined by ultrasound "biparietal diameter" and calculated the last menstrual period were represented in Table 1, Figure 1. 15.4\% pregnant women have 0 week different in gestational age between US and LMP as shown in Figure 2 and LMP as shown in Figure 2 and 38.46\% pregnant women have 1 week different between ultrasound gestational age and LMP gestational age as seen in Figure 3. 23.08\% pregnant women have 2 weeks different between ultrasound gestational age measurement and LMP calculation (Figure 4), 13.46\% pregnant women have 3 weeks different between the gestational age by US and LMP (Figure 5), 3.85\% pregnant women have 4 weeks and 5 weeks different between US gestational age and LMP gestational age (Figure 6, Figure 7) while 1.92\% pregnant woman

Table 1. Number of patients has difference between their US and LMP by weeks.

\begin{tabular}{|c|c|c|c|c|c|c|c|}
\hline \multicolumn{8}{|c|}{ Difference between age by US and BPD by weeks } \\
\hline & O week & 1 week & 2 week & 3 week & 4 week & 5 week & 6 week \\
\hline No. of patient & 8 & 20 & 12 & 7 & 2 & 2 & 1 \\
\hline
\end{tabular}




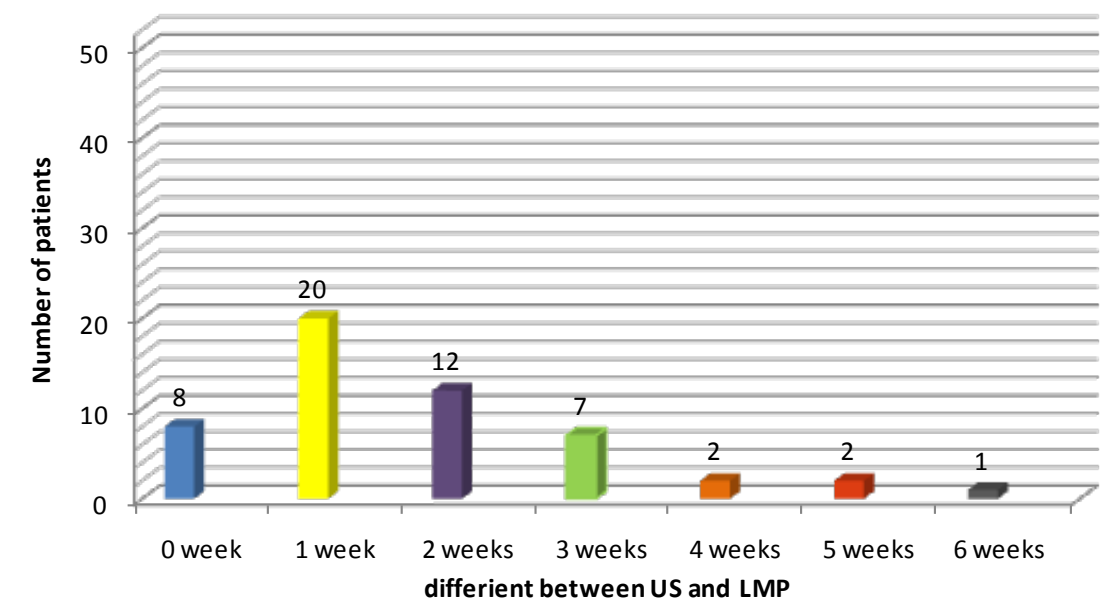

Figure 1. Number of patients has difference between their US and LMP by weeks.

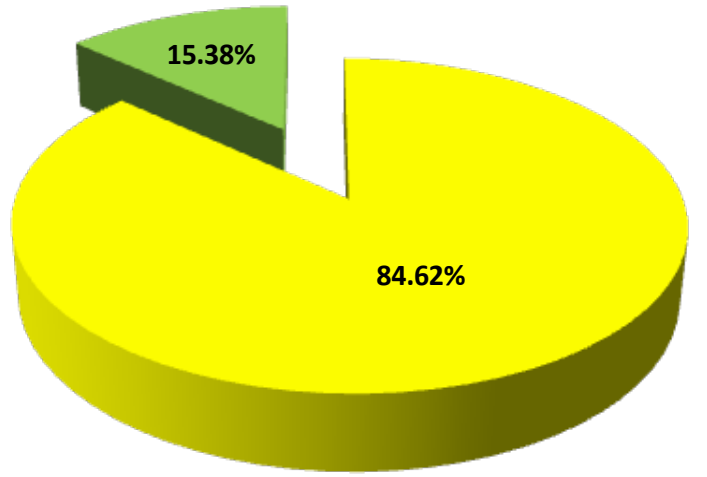

Figure 2. 15.38\% of the patient have no difference between US and LMP.

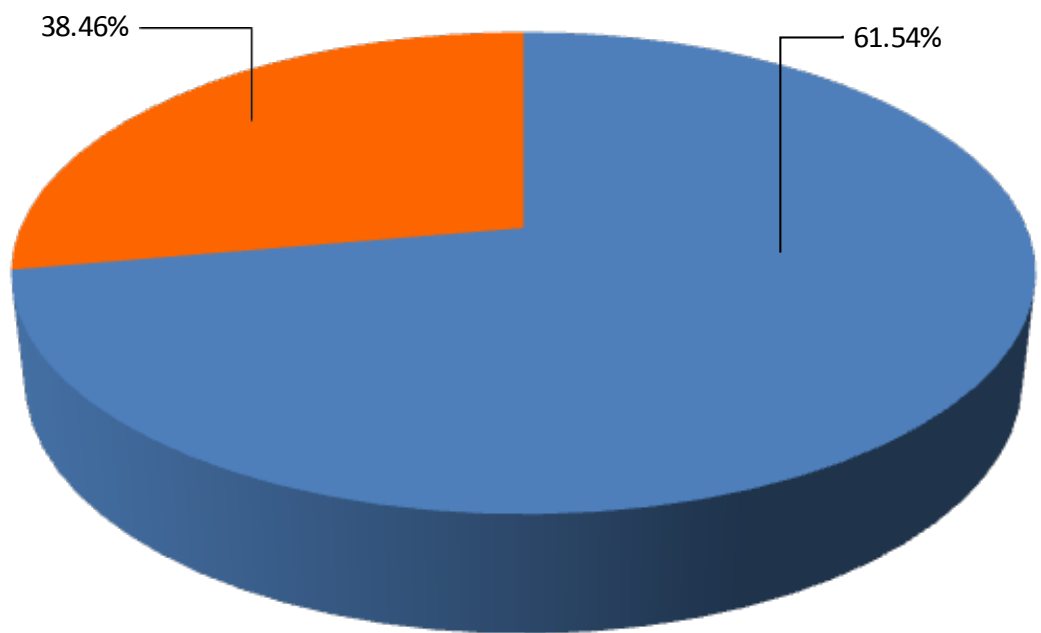

Figure 3. 38.46\% of the patients has 1 week different between US and LMP.

has 6 weeks efferent between US gestational age and LMP gestational age (Figure 8). The relationship between all patients has different in gestational age by US and LMP calculation was shown in Figure 9.

\section{Discussion}

Gestational age, synonymous with menstrual age, is defined in weeks beginning from the first day of the LMP 


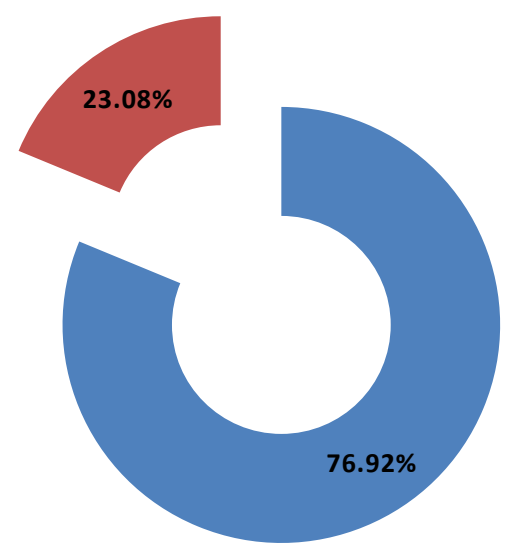

Figure 4. 23.08\% of the patients have 2 week different between US and LMP.

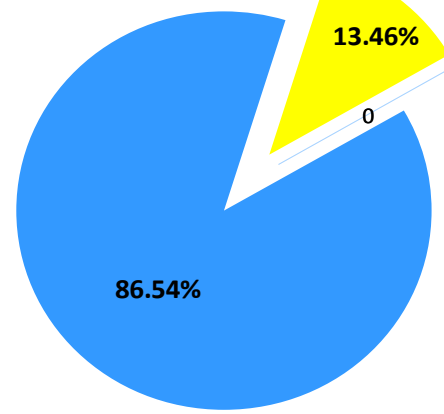

Figure 5. $13.46 \%$ of the patients have 3 week different between US and LMP.

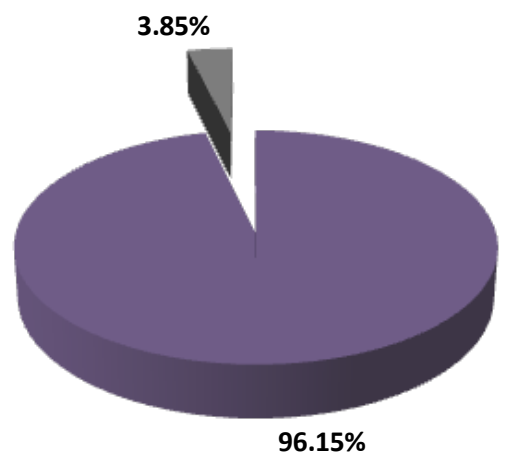

Figure 6. 3.85\% of the patients have 4 week different between US and LMP.

prior to conception. Accurate determination of gestational age is fundamental to obstetric care and is important in a variety of situations. Clinicians may choose to incorporate sonographic measurements into their final estimate of gestational age, as prior research suggests that the use of LMP to determine gestational age can be inaccurate [8] and that even a single second trimester sonogram may be more reliable [9].

The present study showed that $15.38 \%$ of patients don't have any week different between biparietal diameter ultrasound measurement and last menstrual period calculation trimester. while $84.61 \%$ of pregnant women have variable different by weeks in gestational age between ultrasound measurements and last menstrual period calculation this variable could be due to either the patient is given sonographer the wrong day of last menstrual period or the patient doesn't have any previous scan in the first or second trimester [10]. 


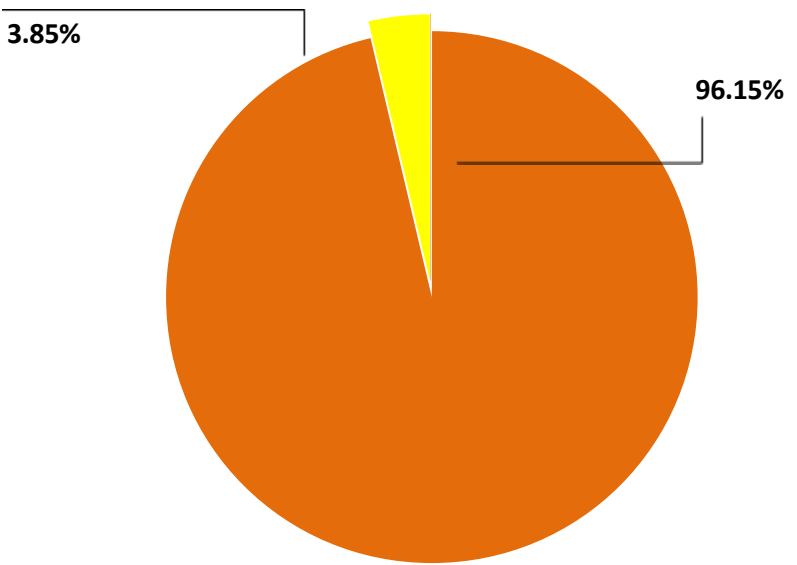

Figure 7. 3.85\% of the patients have 5 week different between US and LMP.

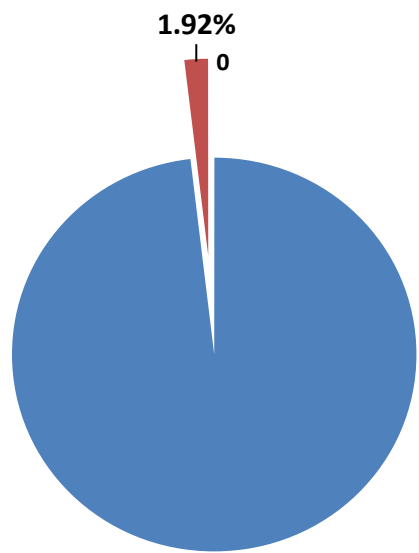

$98.08 \%$

Figure $8.1 .92 \%$ of the patients have 6 week different between US and LMP.

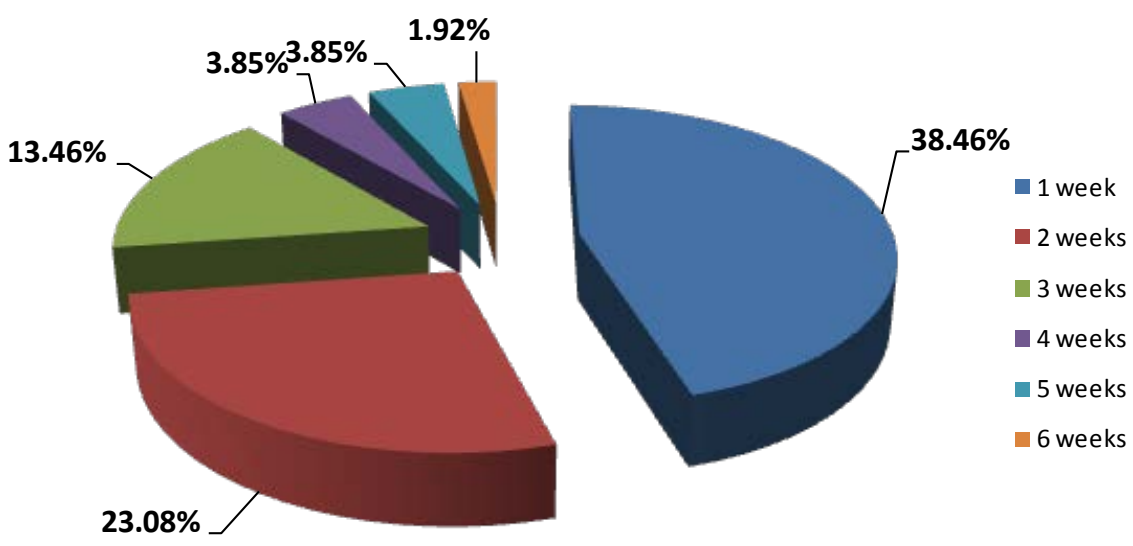

Figure 9. Relation between all patients has different between US and LMP.

The BPD is less reliable in determining gestational age when the intrauterine growth restricted "IUGR" which makes the biparietal growth slowly or patient comes in the last weeks of third trimester "passed 30 weeks"; hence some authors feel that BPD is less reliable and it becomes less accurate with increasing gestational age [11]. Multiple parameters were found to be slightly superior to BPD alone in the estimation of fetal age [12].

It is more challenging to measure the fetal AC than the other parameters. The abdomen has no bright echoes of bone, it is not always symmetrical, and its size will vary with fetal respiration and central body flexion/ex- 
tension. Of all the fetal biometric parameters, this measurement has the most variability as it is somewhat dependent on fetal growth factors and body position [11] [13] [14]. Femur length varies somewhat with ethnicity. Short femurs are commonly a normal variant, however this finding may also indicate fetal growth restriction, aneuploidy, and when severely shortened skeletal dysplasias [15].

The accurate dating of pregnancy is critically important for pregnancy management from the first trimester delivery, and is particularly necessary for determining viability in premature labour and in post-dates deliveries [1].

In my study the almost of patients have US measurement parallel or have a little different to LMP measurement until 29 weeks. The largest difference was after 29 weeks. This means that the accuracy of BPD measurement is less effective. [12] [16] said "the accuracy of predicting gestational age using a fetal femur length was compared to that using the biparietal diameter after 28 weeks gestation in 50 patients. That ultrasonic fetal femur length was more accurate than the biparietal diameter in predicting gestational age in the third trimester. We agree with them that the BPD after 30 weeks should not be measured alone. We have to take more than one measurement beside the biparietal diameter to avoid the wrong gestational age.

\section{Conclusion}

In conclusion, the present study concluded that the main method to follow fetus growth in third trimester not biparietal diameter measurement only. The BPD in third trimester comes to be useless when the patient over 30 weeks and the BPD has to be side with other measurements to emphasize the normal growth of fetus and avoid wrong measurement of ultrasound.

\section{References}

[1] Kalish, R.B. and Chervenak, F.A. (2005) Sonographic Determination of Gestational Age. The Ultrasound Review of Obstetrics \& Gynecology, 5, 254-258. http://dx.doi.org/10.1080/14722240500390166

[2] Brooke, O.G., Butters, F., Wood, C., Bailey, P. and Tukmachi, F. (1981) Size at Birth from 37 - 41 Weeks Gestation: Ethnic Standards for British Infants of Both Sexes. Journal of Human Nutrition, 35, 415-30.

[3] Gabbe, S., Niebyl, J.R. and Simpson J.L. (1990) Obstetrics: Normal and Problem Goldstein, S.R. Early Detection of Pathologic Pregnancy by Transvaginal Ultrasonography. Journal of Clinical Ultrasound, 18, 262-273. http://dx.doi.org/10.1002/jcu.1870180409

[4] Bottomley, C. and Bourne, T. (2009) Dating and Growth in the First Trimester. Best Practice \& Research Clinical Obstetrics \& Gynaecology, 23, 439-452. http://dx.doi.org/10.1016/j.bpobgyn.2009.01.011

[5] Salomon, L.J., Alfirevic, Z., Bilardo, C.M., Chalouhi, G.E., Ghi, T., Kagan, K.O., et al. (2013) ISUOG Practice Guidelines: Performance of First-Trimester Fetal Ultrasound Scan. Ultrasound in Obstetrics \& Gynecology, 41, $102-113$. http://dx.doi.org/10.1002/uog.12342

[6] Caughey, A.B., Nicholson, J.M. and Washington, A.E. (2008) First- vs Second-Trimester Ultrasound: The Effect on Pregnancy Dating and Perinatal Outcomes. American Journal of Obstetrics \& Gynecology, 198, 703-705. http://dx.doi.org/10.1016/j.ajog.2008.03.034

[7] Hughes, R., Aitken, E., Anderson, J., Barry, C., Benton, M. and Elliot, J. (2008) National Institute for Health and Clinical Excellence. Antenatal Care. Routine Care for the Healthy Pregnant Woman. NICE Clinical Guideline 62. RCOG Press, London.

[8] Dietz, P.M., et al. (2007) A Comparison of LMP-Based and Ultrasound-Based Estimates of Gestational Age Using Linked California Livebirth and Prenatal Screening Records. Paediatric and Perinatal Epidemiology, 21, 62-71. http://dx.doi.org/10.1111/j.1365-3016.2007.00862.x

[9] Waldenstrom, U., Axelsson, O. and Nilsson, S. (1990) A Comparison of the Ability of a Sonographically Measured Biparietal Diameter and the Last Menstrual Period to Predict the Spontaneous Onset of Labor. Obstetrics \& Gynecology, 76, 33.

[10] Nyberg, D.A. (2003) Diagnostic Imaging of Fetal Anomalies. 2nd Edition, Lippincott Williams Wilkins, Philadelphia, 32-34.

[11] Chervenak, F.A., Skupski, D.W., Romero, R., Myers, M.K., Smith-Levitin, M., Rosenwaks, Z., et al. (1998) How Accurate Is Fetal Biometry in the Assessment of Fetal Age? American Journal of Obstetrics \& Gynecology, 178, 678-687. http://dx.doi.org/10.1016/S0002-9378(98)70477-6

[12] Wisser, J., Dirschedl, P. and Krone, S. (1994) Estimation of Gestational Age by Transvaginal Sonographic Measurement of Greatest Embryonic Length in Dated Human Embryos. Ultrasound in Obstetrics \& Gynecology, 4, 457-462. 
http://dx.doi.org/10.1046/j.1469-0705.1994.04060457.x

[13] Hadlock, F.P., Harrist, R.B. and Martinez-Poyer, J. (1991) How Accurate Is Second Trimester Fetal Dating? Journal of Ultrasound in Medicine, 10, 557-561.

[14] Benson, C. and Doubilet, P.M. (1991) Sonographic Prediction of Gestational Age: Accuracy of Second- and Third-Trimester Fetal Measurements. American Journal of Roentgenology, 157, 1275-1277. http://dx.doi.org/10.2214/ajr.157.6.1950881

[15] Shalev, E., Feldman, E., Weiner, E. and Zuckerman, H. (1985) Assessment of Gestational Age by Ultrasonic Measurement of the Femur Length. Acta Obstetricia et Gynecologica Scandinavica, 64, 71-74. http://dx.doi.org/10.3109/00016348509154691

[16] Honarvar, M. and Allahyari, M. (1999) Assessment of Gestational Age Based on Ultrasonic Femur Length in Fetus. Acta Medica Iranica, 37, 134-138. 
Scientific Research Publishing (SCIRP) is one of the largest Open Access journal publishers. It is currently publishing more than 200 open access, online, peer-reviewed journals covering a wide range of academic disciplines. SCIRP serves the worldwide academic communities and contributes to the progress and application of science with its publication.

Other selected journals from SCIRP are listed as below. Submit your manuscript to us via either submit@scirp.org or Online Submission Portal.
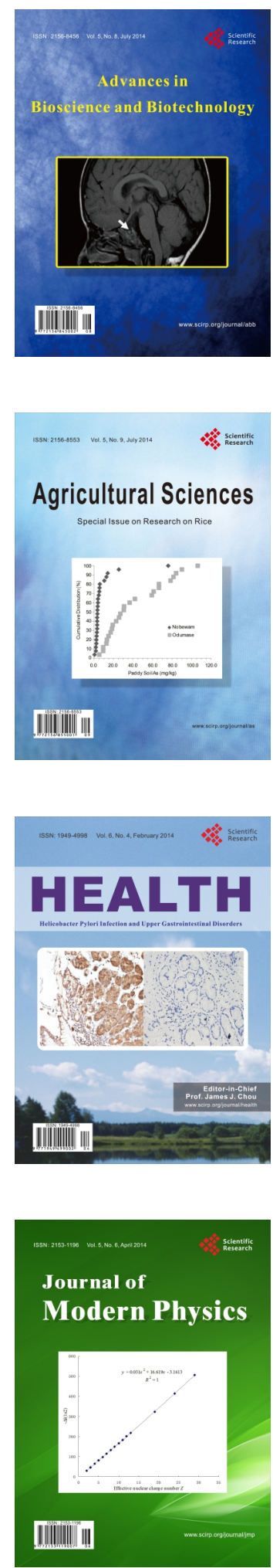
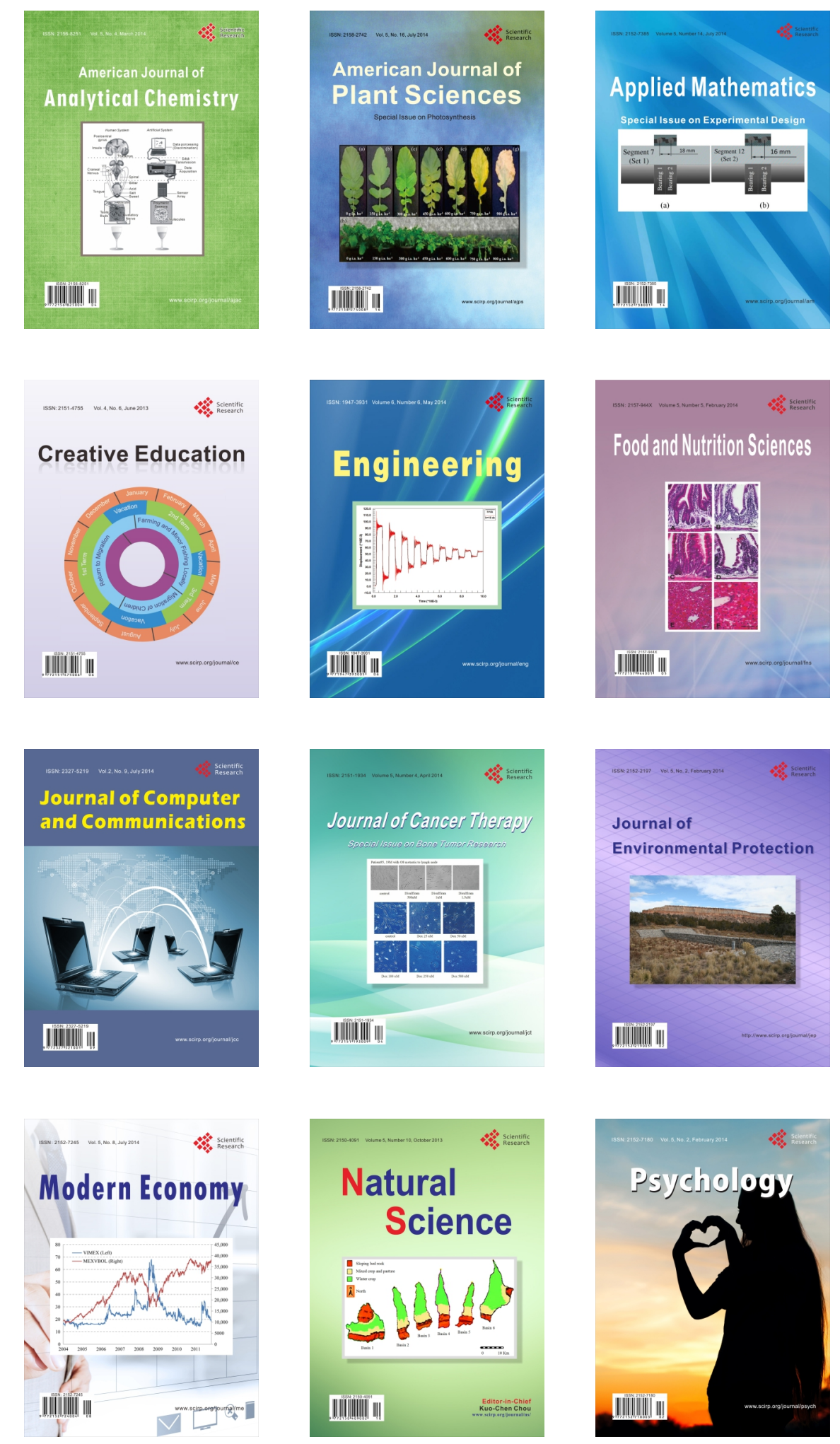